Analytical Methods

\title{
Changes produced in oils during vacuum and traditional frying of potato chips
}

\author{
María José Crosa*, Verónica Skerl, Mónica Cadenazzi, Laura Olazábal, Roberto Silva, Gabriela Suburú, \\ Marina Torres
}

Laboratorio Tecnológico del Uruguay (LATU), Av. Italia 6201, C. P. 11500 Montevideo, Uruguay

\section{A R T I C L E I N F O}

\section{Article history:}

Received 6 September 2012

Received in revised form 16 April 2013

Accepted 29 August 2013

Available online 7 September 2013

\section{Keywords:}

Healthy snacks

Deep frying

Synthetic antioxidant

Natural antioxidant

\begin{abstract}
A B S T R A C T
In this study the effect of vacuum frying (VF) and traditional frying (TF) on oil degradation, fatty acid composition and alpha-tocopherol content was investigated. Two different refined sunflower oils were used: sunflower oil with high oleic acid content (HOSO) and sunflower oil with synthetic antioxidant (tertiary-butylhydroquinone) (TBHQ-SO). Oil degradation was monitored by measuring the free acidity (FFA), peroxide (PV), p-anisidine (p-AV), ) total polar compounds (TPC) and oxidative stability (OE). Oils samples were taken every $4 \mathrm{~h}$ of frying during 10 consecutive days. Values of FFA, p-AV, TPC using TBHQ-SO with traditional frying were $(0.201,207.0,25.0)$ significantly higher than the obtained values with vacuum frying $(0.073,25.8,11.2)$. The same parameters by using HOSO were $(0.327,82.0,21.9)$ with traditional frying and $(0.099,33.3,6.4)$ with vacuum frying. The EO was 2.44 and 7.95 with TBHQ-SO traditional and vacuum frying respectively, and with for HOSO 0.65 and 2.67 , respectively. The polyunsaturated fatty acids percentage decreased in all treatments except in TBHQ-SOv. The alpha-tocopherol content decreased in all treatments at different rates. At the end of the frying processes the percentages of alpha-tocopherol reduction were TBHQ-SOv (4.90\%), TBHQ-SOt (53.62\%), HOSOv (96.87\%), HOSOt (99.76\%).
\end{abstract}

() 2013 Elsevier Ltd. All rights reserved.

\section{Introduction}

The market trend for the consumption of healthier foods has forced the snacks industry to develop alternative technologies to traditional frying, maintaining their characteristic flavour and texture. The vacuum frying (VF) stands out among the studied processes to achieve quality improvement. In this operation, the food is immersed in oil at $40 \mathrm{mmHg}$ in a closed system. The reduced pressure decreases the boiling temperature of water contained in the food, without affecting the characteristic texture of the fried food. The benefits of this technology are associated with frying at lower oil temperatures and reduced exposure to oxygen.

During the last 10 years the nutritional benefits of the vacuum frying have been studied. Dueik, Robert and Bouchon (2009) studied the preservation of colour and flavours in vacuum fried foods. They concluded that the vacuum-fried snacks retain more of their natural colour and flavour due to less oxidation and lower frying temperature. The carrots preserved around $90 \%$ of trans -carotene and $86 \%$ of trans -carotene. Granada, Moreira and Tichy (2004) showed that the process of vacuum frying produced potato chips with $97 \%$ less acrylamide, a potential carcinogen found in chips

\footnotetext{
* Corresponding author. Tel.: +598 26013724.

E-mail addresses: mcrosa@latu.org.uy, mjcrosa.b@gmail.com (M.J. Crosa).
}

produced by the traditional process (atmospheric frying). Garayo and Moreira (2002) showed that vacuum frying of potato achieved chips with $30 \%$ less oil and the same texture and colour characteristics of the traditional frying. Fan, Zhan, Xiao, Sun and Tao (2005), Shyu, Hau and Hwang (1998) studied dehydrated foods produced by vacuum frying and concluded that crispy texture, good colour and flavour were maintained with good retention of nutrients. The vacuum frying technology is being industrially developed. So it is necessary to continue studying, how this new technology affects time of oil usage.

Different types of oils may be used for frying of foods. Their physical and chemical properties influence the degree of oxidation and hydrolysis reactions which occur during frying. Their stability depends on the composition of fatty acids and natural antioxidants as well as frying temperature.

Addition of synthetic antioxidants is one of the major treatments used to maintain the quality of fats and oils during frying. The effectiveness of natural (tocopherols and other phenolic compounds) and synthetic (tertiary butyl hydroquinone (TBHQ), butylated hydroxyanisol (BHA) and butylated hydroxyltoluene (BHT)) antioxidants during the traditional frying process was studied by Marmesat, Morales, Velasco, and Dobarganes (2010). TBHQ is reported as more effective than BHA and BHT, in controlling the oxidation reactions during frying. Similar conclutions were reported 
by other authors (Farhoosh and Tavassoli-Kafrani (2010), Allam and Mohamed (2002)). Regarding natural antioxidant, they concluded as other authors (Fujitani and Ando (1977); Verleyen et al. (2001); Verleyen, Verhe, Huyghebaert; Dewettinck, and de Greyt (2001), Pongracz (1988)), low volatility and rapid degradation of the tocopherols in oil at temperatures between $180^{\circ} \mathrm{C}$ and $220^{\circ} \mathrm{C}$.

The high oleic acid sunflower oil is reported as a better oil compared to regular sunflower, soybean, corn and peanuts oils due to its good thermal and oxidative stability during traditional frying (Roman, Heyd, Broyart, Castillo, and Maillard (2013); Smith, King, and Min (2007); Abdulkarim, Long, Lai, Muhammad, and Ghazali (2007); Marmesat, Morales, Velasco, and Dobarganes (2012)).

There are extensive reports on health benefits due to the consumption of high oleic acid oil because it may decrease the risk of coronary heart disease. Until now it has not been reported how the vacuum frying process influence on oil degradation, fatty acid profile and tocopherols content.

The objective of this study was to evaluate the influence of vacuum frying on oil degradation, fatty acid composition and alphatocopherol content using to different oils: sunflower oil with high oleic acid content and sunflower oil with 200 ppm synthetic antioxidant TBHQ.

\section{Materials and methods}

The studied treatments were: (1) TBHQ-SOv: vacuum frying sunflower oil with TBHQ; (2) TBHQ-SOt: traditional frying - sunflower oil with TBHQ; (3) HOSOv: vacuum frying - high oleic acid content oil; (4) HOSOt: traditional frying - high oleic acid content oil. These treatments correspond to a factorial experiment with two factors: type of frying (vacuum and traditional) and type of oil (sunflower with TBHQ and high oleic acid oil). For each treatment 8 frying cycles of $30 \mathrm{~min}$ each, during 10 days were performed. Oils samples were taken every day and evaluated for free acidity (FFA), peroxide (PV), p-anisidine ( $\mathrm{p}-\mathrm{AV}$ ), oxidative stability (OE), and total polar compounds (TPC), fatty acid composition. Alpha-tocopherol was evaluated every two days.

\subsection{Materials}

The oils used were produced by COUSA (Uruguayan Company). The chemical characteristics of the oils are shown in Table 1.

Table 1

Composition of fresh sunflower oil.

\begin{tabular}{llcc}
\hline & & TBHQ-SO & HOSO \\
\hline Fatty acid composition (relative\%) & C14:0 & 0.02 & 0.04 \\
& C16:0 & 5.64 & 4.16 \\
& C16:1 & 0.02 & 0.10 \\
& C18:0 & 2.82 & 3.26 \\
& C18:1 & 35.97 & 84.61 \\
& C18:2c & 55.04 & 6.04 \\
& C18:2t & 0.17 & 0.04 \\
& C18:3 & 0.07 & 0.05 \\
& C20:0 & 0.09 & 0.26 \\
& C20:1 & 0.04 & 0.23 \\
& C22:0 & 0.17 & 0.86 \\
& SFA & 8.31 & 8.58 \\
& MUFA & 35.86 & 84.94 \\
& PUFA & 55.85 & 6.13 \\
Peroxide value, PV (mol LOOH/L oil) & PUFA/MUFA & 1.55 & 0.07 \\
Polar compounds (\%) & & 2.7 & 6.9 \\
Acidity (\%) & & 9.5 & 3.3 \\
aTocopherols (mg/100 gr) & & 0.06 & 0.03 \\
Oxidative stability & & 60.0 & 59.5 \\
\hline
\end{tabular}

TBHQ-SO: sunflower oil with 200 ppm TBHQ, HOSO: sunflower oil with high oleic content.

\subsection{Experimental determinations}

\subsubsection{Total polar compounds}

Total polar compounds (TPC) estimation was based on dielectric constant changes directly measured on hot oil with Deep Frying Oil Tester testoT270. The Deep Frying Oil Tester operation was verified with the AOCS Official Method Cd 20-91.

\subsubsection{Free fatty acids}

Free fatty acids (FFA), expressed as free oleic acid percentage, was determined using AOCS Method Ca 5a-40.

\subsubsection{Peroxide value}

Peroxide value (PV), expressed in milliequivalents of active oxygen per kilogram $\left(\mathrm{mEq} \mathrm{O}_{2} / \mathrm{kg}\right)$, was determined by AOCS Method Cd 8b-90 (93).

\subsubsection{Anisidine value}

Anisidine value estimates was determined by AOCS Method Cd 18-90.

\subsubsection{Oxidative stability (Rancimat)}

Oxidative stability was estimated by measuring the oxidation induction time, on a Rancimat apparatus (Metrohm 873 Biodiesel Rancimat). Air $(10 \mathrm{~L} / \mathrm{h})$ was bubbled through the oil $(5 \mathrm{~g})$ heated at $110.0 \pm 0.5^{\circ} \mathrm{C}$, with the volatile compounds being collected in water, and the increasing water conductivity continually measured. The time taken to reach the conductivity inflection was recorded.

\subsubsection{Fatty acids composition}

The fatty acid profile analysis was performed by converting glyceride fatty acid to their corresponding methyl esters prior to the analysis by GC-MS (According to AOCS Ce 2-66). The samples were methylated with $14 \% \mathrm{BF} 3$ in methanolic $\mathrm{NaOH}$. The methylated fatty acids were injected in a GC-MS-EI, with split injection system and a HP 88 Agilent column $100 \mathrm{~m}$ length, $0.25 \mathrm{um}$ film thickness and $0.25 \mathrm{~mm}$ internal diameter. The initial oven temperature was $120^{\circ} \mathrm{C}$ and the temperature was increased to $225^{\circ} \mathrm{C}$ (rate of $1{ }^{\circ} \mathrm{C} / \mathrm{min}$ ), after this the column temperature was kept constant for $40 \mathrm{~min}$. The injector temperature was $250^{\circ} \mathrm{C}$, and the source temperature of mass spectrometer was $200^{\circ} \mathrm{C}$. Helium was used as the carrier gas. The fatty acid methyl esters were identified by comparing their retention times and mass spectrum with a mixture standard FAME (37 compounds).

\subsubsection{Alpha-tocopherol content}

Alpha-tocopherol analysis was based on ISO 9936:2006 "Animal and vegetable fats and oils. Determination of tocopherol and tocotrienol contents-Method using HPLC". Briefly, $2.5 \mathrm{~g}$ of oil was dissolved in $25 \mathrm{ml}$ hexane and after filtration the solution was analysed by normal phase HPLC on a Phenomenex Luna Silica column $250 \mathrm{~mm} \times 4.6 \mathrm{~mm} \times 5 \mu$. The mobile phase was a mixture of $99.5 \%$ hexane and $0.5 \%$ isopropanol $(\mathrm{v} / \mathrm{v})$. The eluent flow rate was adjusted to $2 \mathrm{ml} / \mathrm{min}$. A fluorescent detector with excitation wavelength set at $290 \mathrm{~nm}$ and emission wavelength set at 330 was used. The concentrations were expressed in $\mathrm{mg} / 100 \mathrm{~g}$ of oil.

\subsubsection{Traditional frying conditions}

Ten litres of oil was placed in the fryer at atmospheric pressure. On each day of frying 8 batches of 125 grams of $1.5 \mathrm{~mm}$ thick sliced potatoes were processed. The sliced potatoes were deep fried during $2 \mathrm{~min}$ at $180^{\circ} \mathrm{C}$. At the beginning of each day $160 \mathrm{ml}$ of frying oil sample was taken for analysis and replaced with fresh oil to complete the initial volume. 


\subsubsection{Vacuum frying conditions}

Twenty litres of oil bought in the local market were placed in the vacuum fryer. On each day of frying 8 batches of 250 grams of $1.5 \mathrm{~mm}$ thick sliced potatoes were processed.

The sliced potatoes were deep fried during $5 \mathrm{~min}$ at $130^{\circ} \mathrm{C}$ and $40 \mathrm{mmHg}$. After frying the potatoes were centrifugated $30 \mathrm{~s}$ at $30 \mathrm{~Hz}$. At the beginning of each day $320 \mathrm{ml}$ of frying oil sample was taken for analysis and replaced with fresh oil to complete the initial volume.

\subsubsection{Statistical Analysis}

For all oil changes studied, it was carried out an analysis of variance according to a complete randomized block design with 3 replicates, being the treatments TBHQ- SO $v$, TBHQ- SOt, HOSO $v$, HOSOt. The criterion of the blocks was defined prior to the experiment as 3 experimental periods, considering the days 2, 3 and 4 as the beginning (period 1), 5, 6 and 7 as medium (period 2) and 8, 9 and 10 as final (period 3 ). The differences between means were studied according to Tukey test $(p<0.05)$.

\section{Results and discussion}

\subsection{Effect of treatments in oil degradation}

Table 2 shows changes in free fatty acid content, peroxide and anisidine, total polar compounds and oxidative stability during ten days of frying under each treatment.

The free fatty acid content is considered in the food industry as an indicator of the quality of the oil and the degree of hydrolytic degradation during frying. Its increase leads to the development of unpleasant tastes and odors in oils and fried products. The change in acidity during the traditional process was higher on each day of frying, with significant differences in the last period of measurement. HOSOt treatment is the one with major changes, with values of acidity at the end of frying period of 0.33 grams of oleic acid per 100 grams. Supplementary Chart 1 shows the acidity values for each treatment on each day of frying and the means in each period.

\subsection{Changes in peroxide and p-anisidine values}

Primary oxidation reactions cause an increase in the concentration of peroxides to a maximum value beyond which its concentration decreases due to thermal decomposition thereof into carbonyl compounds and aldehydes (Shahidi and Wanasundara, 2002).
Anisidine index is an indicative of the degree of progress of secondary oxidation reactions. It determines the amount of aldehyde present in the oil due to thermal decomposition of the hydroperoxides. For an accurate estimation of the oxidation status, both parameters should be interpreted simultaneously.

The HOSOv treatment is the one with the highest values of concentration of peroxides during the whole frying period, indicating a smaller rate of thermal decomposition of peroxides. PV value is at least 2.9 times higher than in the other treatments in period 1, 2.5 times in period 2 and at least 2.7 times in period 3 . The concentration of peroxides in treatments HOSOt, TBHQ-SOt and TBHQ-SOv has no significant differences between them. But the peroxide amounts in TBHQ-SOv treatment, are higher than in the TBHQSOt at least 2.32 times in period 2 and 1.86 times in the period 3 . These higher levels of peroxide values in vacuum than in traditional might be explained by smaller rate of thermal decomposition of peroxides. The p-anisidine values in vacuum treatments are significantly lower than in traditional treatments, representing a clear reduction of the rate of secondary oxidation due to the conditions of vacuum frying. These significative lower levels of $\mathrm{p}$-anisidine, are related to the formation of oxidation products and are also consistent with TPC and oxidative stability values found. These results are showed in Supplementary Chart 2 and 3.

The p-anisidine value in TBHQ-SOt treatment is significantly higher in all periods However, treatment TBHQ-SOv is the one with lowest p-anisidine value. Stability of oil with TBHQ antioxidant during vacuum frying shows its effectiveness in this process which is carried out at temperature of $120^{\circ} \mathrm{C}$. This is consistent with reports of volatilisation and degradation of the TBHQ antioxidant at temperatures above $150^{\circ} \mathrm{C}$ (Dobarganes, Perez-Camino, \& Gutierrez Rosales, 1986; Lin, Warner, \& Fazio, 1981; Warner, Danils, Lin, Joe, \& Fazio, 1986) and its effective action as an antioxidant at lower temperatures, as in the case of vacuum frying.

\subsection{Changes in total polar components and oxidative stability}

The determination of total polar compounds (TPC) in frying oil provides the most reliable measure of the extent of oxidative degradation (Andrali, Sandhya, Sunkireddy, \& Ramakrishna, 2010). The results showed that the contents of TPC increased almost linearly with the frying time similar to that reported by Andrali et al. (2010) and Abdulkarim et al. (2007). The increase in the extent of polar compounds in the oil indicates the formation of compounds of high polarity such as triacylglycerols, secondary oxida-

Table 2

Oil degradation during frying.

\begin{tabular}{|c|c|c|c|c|c|c|c|c|c|c|}
\hline $\mathrm{P}$ & FFA & & PV & & $\mathrm{p}-\mathrm{Av}$ & & TPC & & EO & \\
\hline 1 & HOSOt a & $0.105 \pm 0.014$ & HOSOv a & $17.56 \pm 0.75$ & TBHQ-SOt a & $121.1 \pm 7.0$ & TBHQ-SOTa & $15.0 \pm 1.0$ & TBHQ-SOv a & $12.96 \pm 0.51$ \\
\hline 1 & TBHQ-SOt a & $0.096 \pm 0.017$ & TBHQ-SOt b & $6.15 \pm 0.93$ & HOSOt b & $61.9 \pm 5.7$ & TBHQ-SOv b & $10.2 \pm 0.8$ & HOSOv b & $7.78 \pm 0.51$ \\
\hline 1 & HOSO $v$ a & $0,066 \pm 0.014$ & HOSOt b & $5.71 \pm 0.75$ & TBHQ-SOv c & $15.4 \pm 5.7$ & HOSOt b & $10.1 \pm 0.8$ & TBHQ-SOt c & $3.4 \pm 0.63$ \\
\hline 1 & TBHQ-SO $v$ a & $0.063 \pm 0.014$ & TBHQ-SOv b & $5.10 \pm 0.75$ & HOSOv c & $14.4 \pm 5.7$ & HOSOv c & $4.2 \pm 0.8$ & HOSOt d & $0.54 \pm 0.51$ \\
\hline 2 & HOSOt a & $0.210 \pm 0.014$ & HOSOv a & $14.10 \pm 0.76$ & TBHQ-SOt a & $187.0 \pm 9.9$ & TBHQ-SOt a & $20.5 \pm 1.4$ & TBHQ-SOv a & $9.99 \pm 0.37$ \\
\hline 2 & TBHQ-SOt ab & $0.146 \pm 0.025$ & TBHQ-SOv b & $5.57 \pm 0.76$ & HOSOt b & $75.4 \pm 5.7$ & HosOt a & $16.6 \pm 0.8$ & HOSOv b & $4.75 \pm 0.37$ \\
\hline 2 & $\mathrm{HOSO} v \mathrm{~b}$ & $0.084 \pm 0.014$ & HOSOt b & $4.52 \pm 0.76$ & HOSOv c & $29.5 \pm 5.7$ & TBHQ-SOv b & $10.8 \pm 0.8$ & TBHQ-SOt bc & $2.66 \pm 0.65$ \\
\hline 2 & TBHQ-SO $v$ b & $0.068 \pm 0.014$ & TBHQ-SOt b & $2.40 \pm 1.32$ & TBHQ-SOv c & $20.3 \pm 5.7$ & HOSOv c & $5.5 \pm 0.8$ & HOSOt c & $0.51 \pm 0.37$ \\
\hline 3 & HOSOt a & $0.327 \pm 0.014$ & HOSOv a & $11.43 \pm 0.76$ & TBHQ-SOt a & $207.0 \pm 5.7$ & TBHQ-SOt a & $25.0 \pm 1.0$ & TBHQ-SOv a & $7.95 \pm 0.29$ \\
\hline 3 & TBHQ-SO $t$ b & $0.201 \pm 0.017$ & TBHQ-SOv c & $4.20 \pm 0.76$ & HOSOt b & $82.0 \pm 5.7$ & HOSOt a & $21.9 \pm 0.8$ & HOSOv b & $2.67 \pm 0.29$ \\
\hline 3 & HOSO $v$ c & $0.099 \pm 0.014$ & HoSOt c & $3.15 \pm 0.76$ & HOSOv c & $33.3 \pm 5.7$ & TBHQ-SOv b & $11.2 \pm 0.8$ & TBHQ-SOt b & $2.44 \pm 0.36$ \\
\hline 3 & TBHQ-SO $v$ c & $0.073 \pm 0.014$ & TBHQ-SOt c & $2.25 \pm 0.76$ & TBHQ-SOv c & $25.8 \pm 5.7$ & HOSOv c & $6.4 \pm 0.8$ & HOSOt c & $0.65 \pm 0.29$ \\
\hline
\end{tabular}

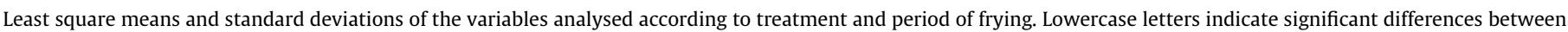
means by Tukey test $(p<0.05)$. (FFA: g oleic acid/100 g; PV: meq $\mathrm{O}_{2} / \mathrm{kg}$ ).

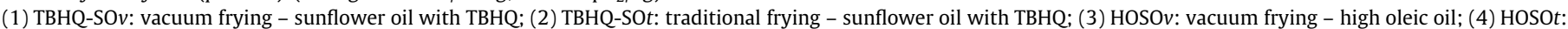
traditional frying - high oleic acid content. 
tion reactions products. TPC values at the end of the vacuum frying process HOSOv and TBHQ-SOv were $11.2 \%$ and $6.5 \%$, while values at TBHQ-SOt and HOSOt processes were significantly higher, $25 \%$ and $22 \%$ respectively. The initial TPC value of $\mathrm{HO}$ is lower than in TBHQ-SO, so the increment in TPC content during frying was higher for high oleic oil. Values in the HOSOt treatment was 5 times greater compared respect to initial value in the second period, and 6.6 times in the third period. The TBHQ-SOt showed a lower polar components increment, the change is 2.1 times in second period and 2.6 times in the third period. This higher speed of polar component formation in HOSOt can be related whit the lowest oxidative stability measured by rancimat method.

The rancimat method is frequently used for predicting oxidative stabilities under heating conditions and is known as induction time. In order to understand the changes in the oxidative stability during frying sessions, samples were taken each day and evaluated with Rancimat test. Clearly different results were observed for all treatments (Table 3 ). The traditional process presented a significative reduction at the second day and remained constant until the end of the process. The vacuum process had a gradual decrease in the oxidative stability. The TBHQ-SOv treatment had significative higher values during all the frying period, the induction time value in the last day is similar to the values obtained in the first day of traditional process. These results are showed in Supplementary Chart 5.

\subsection{Change of the fatty acid composition}

The impact of the fatty acid composition on lipid oxidation was evaluated by measuring the relative percentage of unsaturated, polyunsaturated and saturated fatty acids. Roman et al. (2013) studied the effect on PUFA/MUFA ratio in sunflower oil. They reported a higher reactivity of PUFA than MUFA (-linolenic acid > linoleic acid > oleic acid), as had previously been shown by different studies (Martin-Polvillo, Marquez-Ruiz, and Dobarganes (2004), Parker, Adams, Zhou, Harris, and Yu (2003)).

When comparing the relative percentage of fatty acids during frying sessions, the reduction of polyunsaturated fatty acids observed in high oleic acid sunflower oil was significantly higher than in sunflower oil with TBHQ. This result could be explained due to the presence of the synthetic antioxidant TBHQ.

The reduction of polyunsaturated fatty acids in HOSO submitted to traditional process (HOSOt) is significantly higher pronounced than in vacuum treatment (HOSOv). This result could be explained
Table 4

Alpha-tocopherol degradation during frying.

\begin{tabular}{llr}
\hline $\mathrm{P}$ & & $\alpha$-Tocopherol \\
\hline 1 & TBHQ-SOv a & $-1.96 \pm 6.95$ \\
1 & TBHQ-SOt ab & $-21.71 \pm 6.95$ \\
1 & HOSOv b & $-45.31 \pm 6.95$ \\
1 & HOSOt c & $-99.89 \pm 6.95$ \\
3 & TBHQ-SOv a & $-4.90 \pm 2.36$ \\
3 & TBHQ-SOt b & $-53.62 \pm 2.36$ \\
3 & HOSOv c & $-96.87 \pm 2.36$ \\
3 & HOSOt c & $-99.76 \pm 2.36$ \\
\hline
\end{tabular}

Least square means and standard deviations of the variables analysed according to treatment and period of frying. Lowercase letters indicate significant differences between means by Tukey test $(p<0.05)$. Alpha-tocopherol degradation is expressed in percentage of change compared with the oil without processing.

because in vacuum treatment there was no air. Then, the oxidation of unsaturated fatty acids during heating is lower.

There is no reduction of polyunsaturated fatty acids during hole the frying period in TBHQ-SOv. This result is in agreement with the other parameters evaluated.

\subsection{Change in alpha-tocopherol content}

Vitamin E is used as a generic descriptor for all tocopherol and tocotrienol derivatives which qualitatively exhibit the biologic activity of alpha-tocopherol. This vitamin is an important vegetable oil component contributing to nutritional value of oils. It presence is also important from the technological point of view due to its antioxidant activity, being generally oxidised to quinidine and dimmers while protecting the fat (Casal, Malheiro, Sendas, Oliveira, and Pereira (2010)).

Alpha-tocopherol is the vitamer which is present in higher amount in sunflower oil (Firestone, 1999) this is why we analysed only this vitamer.

Alpha-tocopherol degraded sharply in HOSOt treatment, being practically non-detectable after the second day of frying. Degradation in HOSOv is slower than in HOSOt however, low value is present at the end of the studied period. On the contrary, alpha-tocopherol levels were only slightly reduced in TBHQ-SOv treatment, the loss at the end of the studied period was only $5 \%$. The loss of alpha-tocopherol in each treatment was in agreement with the results of oxidative stability. In the Table 4 is shown alpha-tocopherol degradation expressed in percentage of change compared with the oil without processing.

Table 3

Changes in fatty acid composition during frying ( $\mathrm{g} / 100 \mathrm{~g}$ fatty acids).

\begin{tabular}{|c|c|c|c|c|c|c|}
\hline \multirow{2}{*}{$\frac{P}{1}$} & \multicolumn{2}{|c|}{ Mono unsaturated } & \multicolumn{2}{|c|}{ Poli unsaturated } & \multicolumn{2}{|l|}{ Saturated } \\
\hline & HOSOt a & $8.96 \pm 1.02$ & HOSOv a & $12.23 \pm 3.61$ & TBHQ-SOt a & $4.63 \pm 6.1$ \\
\hline 1 & HOSOv b & $3.63 \pm 1.02$ & TBHQ-SOv a & $1.36 \pm 3.61$ & TBHQ-SOv a & $-11.53 \pm 7.0$ \\
\hline 1 & TBHQ-SOt c & $2.63 \pm 0.88$ & TBHQ-SOt a & $-2.51 \pm 3.12$ & HOSOv b & $-41.64 \pm 7.0$ \\
\hline 1 & TBHQ-SOv c & $0.57 \pm 1.02$ & HOSOt b & $-52.47 \pm 3.61$ & HOSOt b & $-49.76 \pm 7.0$ \\
\hline 2 & HOSOt a & $9.64 \pm 0.85$ & TBHQ-SOv a & $0.14 \pm 3.61$ & TBHQ-SOt a & $7.33 \pm 6.47$ \\
\hline 2 & HOSOv a & $6.95 \pm 0.85$ & TBHQ-SOt ab & $-4.49 \pm 3.61$ & TBHQ-SOv a & $-6.99 \pm 6.47$ \\
\hline 2 & TBHQ-SOt a & $5.01 \pm 0.85$ & HOSOv b & $-17.45 \pm 3.61$ & HOSOt b & $-50.85 \pm 6.47$ \\
\hline 2 & TBHQ-SOv a & $1.19 \pm 0.85$ & HOSOt c & $-61.88 \pm 3.61$ & HOSOv b & $-52.21 \pm 6.47$ \\
\hline 3 & HOSOt a & $10.06 \pm 2.46$ & TBHQ-SOv a & $3.04 \pm 2.73$ & TBHQ-SOt a & $10.76 \pm 7.66$ \\
\hline 3 & TBHQ-SOt a & $7.12 \pm 2.46$ & TBHQ-SOt a & $-6.41 \pm 2.36$ & TBHQ-SOv a & $-18.09 \pm 8.84$ \\
\hline 3 & HOSOv a & $1.69 \pm 2.46$ & HOSOv b & $-21.85 \pm 3.34$ & HOSOv b & $-45.33 \pm 10.83$ \\
\hline 3 & TBHQ-SOv a & $-0.47 \pm 2.46$ & HOSOt c & $-65.98 \pm 3.34$ & HOSOt b & $-50.93 \pm 10.83$ \\
\hline
\end{tabular}

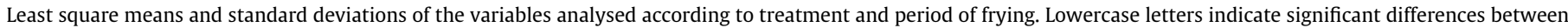
means by Tukey test $(p<0.05)$. 


\section{Conclusions}

This study demonstrated the complexity of lipid oxidation phenomena affected by frying process and chemical oil composition. Vacuum frying achieves a significant decrease in the rate of deterioration reactions in oil. The synthetic antioxidant TBHQ in vacuum frying process has a high effective antioxidant activity. Sunflower oil with the antioxidant showed very slight changes in all parameters studied peroxide and p-anisidine values, total polar content, oxidative stability, fatty acid composition and alpha-tocopherol content during the ten days of frying.

It was observed a significant increase in the usage time of the oil with vacuum frying process compared with the traditional process.

\section{Acknowledgments}

The authors are grateful to ANII, DETRICAR S.A. y LATU (Uruguay) for the financial support. We also thank Elisa Fernandez, Cecilia Silveira and Ines Deandreis for their cooperation during experimentation and laboratory analysis.

\section{Appendix A. Supplementary data}

Supplementary data associated with this article can be found, in the online version, at http://dx.doi.org/10.1016/j.foodchem.2013. 08.132 .

\section{References}

Abdulkarim, S. M., Long, K., Lai, O. M., Muhammad, S. K. S., \& Ghazali, H. M. (2007) Frying quality and stability of high oleic Moringa oleifera seed oil in comparison with other vegetable oils. Food Chemistry, 105, 1382-1389.

Allam, S. S. M., \& Mohamed, H. M. A. (2002). Thermal stability of some commercial natural and synthetic antioxidants and their mixtures. Journal of Food Lipids, 9, 277-293.

Andrali, K., Sandhya, R., Sunkireddy, Y. R., \& Ramakrishna, C. (2010). Quality changes in trans and trans free fats/oils and products during frying. European Food Research Technology, 230, 803-811.

Casal, S., Malheiro, R., Sendas, A., Oliveira, B., \& Pereira, J. A. (2010). Olive oil stability under deep-frying conditions. Food and Chemical Toxicology, 48, 2972-2979.

Dobarganes, M. C., Perez-Camino, M. C., \& Gutierrez Rosales, F. (1986). Protective action of the antioxidants BHT and BHA in fats heated at elevated temperature. Grasas y Aceites, 37, 262-266.

Dueik, V., Robert, P., \& Bouchon, P. (2009). Vacuum frying reduces oil uptake and improves the quality parameter of carrots crisps. Food Chemistry, 119, 1143-1149.
Fan, L., Zhang, M., Xiao, G., Sun, J., \& Tao, Q. (2005). The optimization of vacuum frying to dehydrate carrot chips. International Journal of Food Science and Technology, 40, 911-919.

Farhoosh, R., \& Tavassoli-Kafrani, M. H. (2010). Polar compounds distribution of sunflower oil as affected by unsaponifiable matters of Bene hull oil (BHO) and tertiary-butylhydroquinone (TBHQ) during deep-frying. Food Chemistry, 122, $381-385$.

Firestone, D. (1999). Physical and chemical characteristics of oils, fats, and waxes. American Oil Chemist Society, 100.

Fujitani, T., \& Ando, H. (1977). Oxidative dimerization of tocopherols during the course of thermal oxidation of saturated and unsaturated triglycerids. Journal of Japan Oil Chemist's Society, 26, 768-773.

Garayo, J., \& Moreira, R. (2002). Vacuum frying of potato chips. Journal of Foof Engineering, 55, 181-191.

Granada, C., Moreira, R. G., \& Tichy, S. E. (2004). Reduction of acrylamide formation in potato chips by low-temperature vacuum frying. Journal of Food Science, 69.

Lin, F. S., Warner, C. R., \& Fazio, T. (1981). Alteration of phenolic antioxidants in heated vegetable oils. Journal of the American Oil Chemist's Society, 58, 789-791.

Marmesat, S., Morales, A., Velasco, J., \& Dobarganes, M. C. (2010). Action and fate of natural and synthetic antioxidants during frying. Grasas y Aceites, 61(4), 333-340.

Marmesat, S., Morales, A., Velasco, J., \& Dobarganes, M. C. (2012). Influence of fatty acid composition on chemicals changes in blend of sunflower oils during thermoxidation and frying. Food Chemistry, 135, 2333-2339.

Martin-Polvillo, M., Marquez-Ruiz, G., \& Dobarganes, M. C. (2004). Oxidative stability of sunflower oils differing in unsaturation negree Turing long-term storage at room temperature. Journal of the American Oil Chemists' Society, 81(6), 577-583.

Parker, T. D., Adams, D. A., Zhou, K., Harris, M., \& Yu, L. (2003). Fatty acid composition and oxidative stability of cold-pressed edible seed oils. Journal of Food Science, 68(4), 1240-1243.

Pongracz, V. G. (1988). Hitzestabilitat der tocopherole. Fat Science Technology, 90, $247-251$.

Roman, O., Heyd, B., Broyart, B., Castillo, R., \& Maillard, M. (2013). Oxidative reactivity of unsaturated fatty acids from sunflower, high oleic sunflower and rapeseed oils subjected to heat treatment, under controlled conditions. Food Science and Technology, 52, 49-59.

Shahidi, F., \& Wanasundara, U. N. (2002). Methods for measuring oxidative rancidity in fats and oils. In C. C. Akoh \& D. B. Min (Eds.). Food lipids: Chemistry, nutrition and biotechnology (2nd ed.), pp. 465-482). New York: Marcel Dekker, Inc.

Shyu, S., Hau, L., \& Hwang, S. (1998). Effect of vacuum frying on the oxidative stability of oils. Journal of the American Oil Chemists' Society, 75, 1393-1398.

Smith, S. A., King, R. E., \& Min, D. B. (2007). Oxidative and thermal stabilities of genetically modified high oleic sunflower oil. Food Chemistry, 102, 1208-1213.

Verleyen, T., Kamal-Eldin, A., Dobarganes, M. C., Verhe, R., Dewettinck, K., \& Huyghebaert, A. (2001a). Modeling of ÿ-tocopherol loss and oxidation products formed during thermoxidation in triolein and tripalmitin mixtures. Lipids, 36, 719-726.

Verleyen, T., Verhe, R., Huyghebaert, A., Dewettinck, K., \& de Greyt, W. (2001b). Identification of ÿ-tocopherol oxidation products in triolein at elevated temperatures. Journal of Agriculture and Food Chemistry, 49, 1508-1511.

Warner, C. R., Danils, H. D., Lin, F. S. D., Joe, F. L., \& Fazio, T. (1986). Fate of antioxidants and antioxidant-derived products in deep fat frying and cookie baking. Journal of Agricultural and Food Chemistry, 34, 1-5. 